\title{
Squamous cell carcinoma of the dorsal tongue
}

\author{
Keiichi Ohta DDS, Hitoshi Yoshimura DDS PhD
}

- Cite as: CMAJ 2019 November 25;191:E1310. doi: 10.1503/cmaj.190677

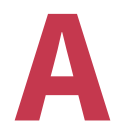

67-year-old man presented with a 6-month history of a mass on the dorsum of the tongue. He had noted slight pain at the site 10 years earlier. He had a 24-pack-year history of smoking and rarely drank alcohol. Examination showed a well-circumscribed mass on the dorsal tongue without induration (Figure $1 \mathrm{~A}$ ) or cervical lymphadenopathy. Excisional biopsy was performed, and microinvasive squamous cell carcinoma was diagnosed (Figures $1 B$ and $1 C$ ). Immunohistochemical testing showed the tumour to be positive for vimentin and negative for periodic acid-Schiff-diastase, neuron-specific enolase, TFE3 and S100, excluding granular cell tumour. We recommended additional resection to achieve adequate free margins, but the patient requested observation. We did not perform prophylactic neck dissection or sentinel lymph node biopsy, considering the minimal risk of lymph node metastasis of this tumour. ${ }^{1}$ No evidence of recurrence or distant metastasis was found at monthly follow-up examinations over the course of 12 months or on computed tomography at 4 months.

Squamous cell carcinoma of the tongue is the most common oral cancer, usually occurring in the lateral tongue., ${ }^{2,3}$ Generally, it occurs in middle-aged men. ${ }^{4}$ Smoking and alcohol consumption are risk factors. ${ }^{4}$ Patients may present with pain or a burning sensation of the tongue. Squamous cell carcinoma of the dorsal tongue, a less common presentation, has reportedly occurred from long-standing oral lichen planus, considered a precancerous condition. ${ }^{2,3}$ In our case, we presumed that the lesion had long been in a precancerous state. The differential diagnosis of this tumour includes granular cell tumour, medial rhomboid glossitis, amyloidosis and oral lichen planus. ${ }^{2}$ Biopsy with immunohistochemical examination is important to avoid misdiagnosis. Histopathologically, squamous cell carcinoma shows invasive islands and cords of malignant epithelial cells. Wide surgical resection or radiotherapy is the conventional treatment for early-stage disease, with reconstructive surgery for advanced-stage disease. ${ }^{2}$

\section{References}

1. Sridharan G, Alex S, Bhandare $\mathrm{P}$, et al. Microinvasive oral squamous cell carcinoma - a clinicopathological study. Med Res Arch 2017;5.

2. Okubo M, Iwai T, Nakashima H, et al. Squamous cell carcinoma of the tongue dorsum: incidence and treatment considerations. Indian J Otolaryngol Head Neck Surg 2017;69:6-10.

3. Takemoto T, Akita T, Saito M, et al. Squamous cell carcinoma initially arising in the midline of the dorsum of the tongue in a young adult: a case report and review of the literature. J Oral Maxillofac Surg Med Pathol 2019;31:185-8.

4. Mangold AR, Torgerson RR, Rogers RS. Diseases of the tongue. Clin Dermatol 2016; 34:458-69.
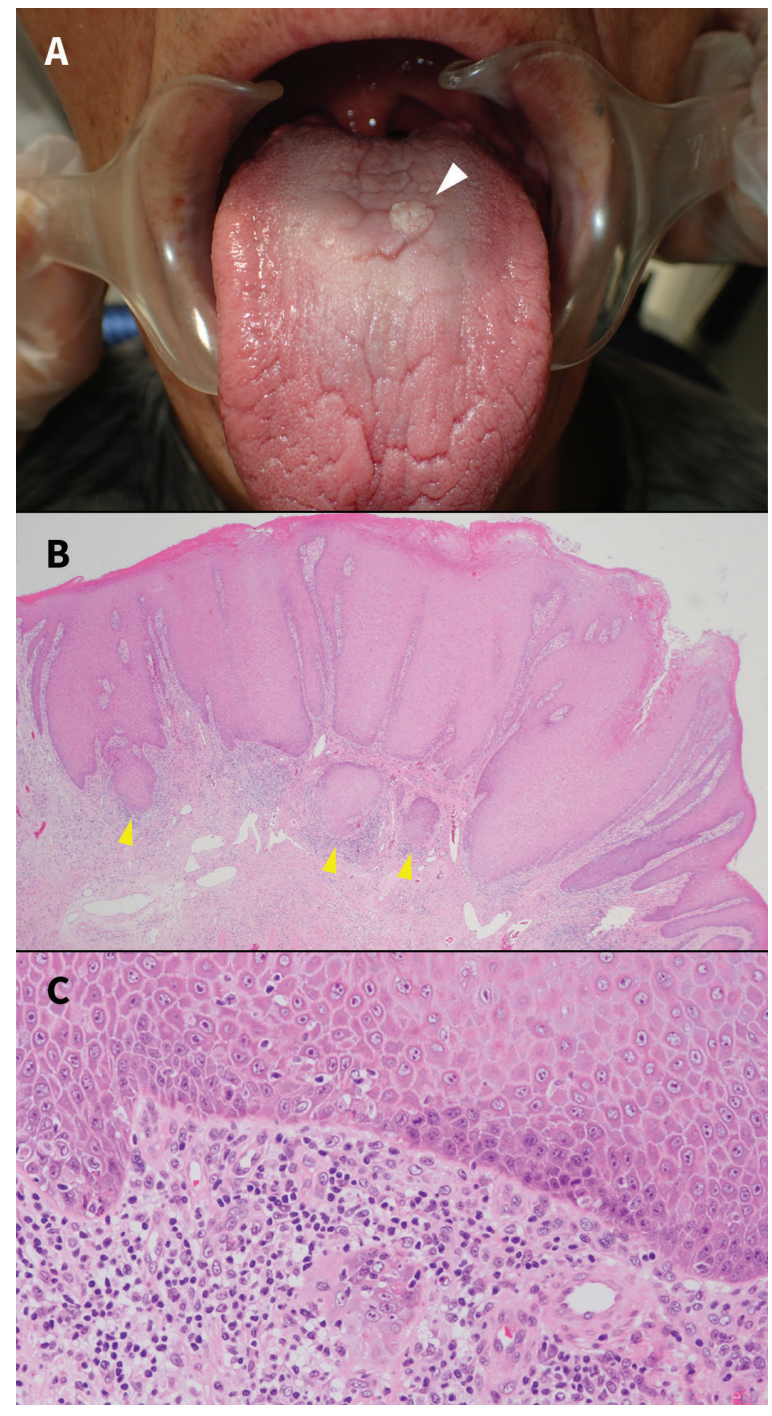

Figure 1: (A) Well-circumscribed, irregular $8 \times 7 \mathrm{~mm}$ mass in the dorsal tongue midline (arrow) in a 67-year-old man. Histopathological examination with hematoxylin-eosin staining showed (B) thickened epithelium with infiltration beneath the basement membrane (arrows) (magnification $\times 40$ ) and $(C)$ nuclear enlargement and increased mitotic figures in the basal layer (magnification $\times 400$ ), consistent with squamous cell carcinoma.

\section{Competing interests: None declared.}

This article has been peer reviewed.

The authors have obtained patient consent.
Affiliation: Department of Dentistry and Oral Surgery, Unit of Sensory and Locomotor Medicine, Division of Medicine, Faculty of Medical Sciences, University of Fukui, Fukui, Japan
Correspondence to: Keiichi Ohta, kohta@g.u-fukui.ac.jp 